\title{
The hole-drilling technique for the stresses measurements in brick masonries
}

\author{
S. Sánchez-Beitia \\ Faculty of Architecture, Basque Country University, Spain
}

\begin{abstract}
This paper deals with the application of the hole-drilling technique for the measurement of the stresses in the structural elements of cultural heritage constructions. The method involves glued strain gages at the surface of a piece of masonry. The drilling device is a diamond crown extracting a cylinder of material in a concentric way with the circumference $(12 \mathrm{~cm}$ diameter $)$ of the strain gages position. At least three strain gages are placed in the area under consideration. The strain gages record the strains originated by stress relaxation after extracting a round of $3.6 \mathrm{~cm}$ diameter and $4.8 \mathrm{~cm}$ in depth. The stresses before drilling can be deduced with an appropriate mathematical scheme. This experimental procedure has been called Donostia Method by the author in previous works being an ASTM technique. Brick masonry has been built and loaded at the laboratory in order to check the method before actual works on site take place. This constructive element is widely used in cultural heritage constructions. A known stress has been applied to the masonry in order to compare it with the results obtained by means of the hole-drilling technique. The results obtained are very close to what is expected. The technique is harmless for the material and allows the deduction of the principal stresses and their directions for a bi-dimensional state of stresses on the surface. In addition, the method allows for the measurement of tensile stresses. Thus the hole-drilling technique is a minor-destructive method of testing giving more information than the flat jacks technique. The deduction of the stresses is strongly influenced by the constants that relate them with strains measured after drilling. This paper analyzes two different methods to deduce such constants.
\end{abstract}

Keywords: architectural heritage, structural analysis, the Donostia Method, hole-drilling technique. 


\section{The hole-drilling technique in architectural heritage}

The hole-drilling technique is widely employed to obtain the Residual Stresses near the surface of a material by using a three-element strain gage rosette $[1,2]$. The application of this technique to architectural heritage (called the Donostia method by the author in previous publications, [3 to 9]) is based on the utilization of strain gages to get the strains caused by stress relaxation when a zone of material is eliminated. Over a circumference of $12 \mathrm{~cm}$ diameter three strain gages are glued. The strain gages are connected to a strain-recording instrument measuring the fluctuations around the zero until their stabilization. After reaching the stabilization a drill, $3.6 \mathrm{~cm}$ diameter and $4.8 \mathrm{~cm}$ depth, concentric with the circumference of position of the strain gages has been done. The depth of the drill has to be 0.4 times the diameter of the circumference of strain gages. The drilling device is a diamond crown extracting a round of material its diameter being chosen due to the existent crowns in the market allowing an easy manipulation. After the drill is completed the strains are once more measured during 180 minutes at least until their new stabilization. Such strains are originated by the stress relaxation due to the removal of the round and are caused by the existing stresses before the drill operation. The procedure here described is a particularisation of the hole-drilling technique used to deduce the residual stresses according to the Standard ASTM E837-95 (it exists a further actualization of the year $2001[1,2])$. Firstly strain gages of $6 \mathrm{~mm}$ length have to be chosen, at least ten times larger than the grain size of the tested materials. The experimental dimensions (size of strain gages, dimensions of drilling, etc...) proposed by such Standard are thirty times lower than the dimensions that can be used on rock, brick or mortar as building materials. However, the relation between such dimensions has been faithfully followed in order to assure the relaxation of stresses in the measured area. In previous works it has been experimentally checked that these dimensions assure the complete stress relaxation by the material extraction $[3,4]$. For the dimensions used on masonries there is not a standard drill device to follow the exact procedure proposed by the ASTM Standard. That is to say the procedure here described and the hole-drilling technique are similar, nevertheless the experimental conditions are very different. The previous ASTM Standard sets two methods to get the constants relating the recorded strains to the stresses that cause them. The first method establishes that these constants (called $A_{t}$ and $B_{t}$ ) are related with the Poisson Coefficient (v), the Young Modulus (E) and two dimensionless parameters " $a$ " and "b" that include the geometrical conditions of the test. In this case the constants are as follows:

$$
\begin{gathered}
A_{t}=-4((1+v) / 2 E) a \\
B_{t}=-4(1 / 2 E) b
\end{gathered}
$$

After the value of the constants $A_{t}$ and $B_{t}$ have been obtained, the stresses near the round before the drill are deduced by means of the following expressions:

$$
\begin{gathered}
\sigma_{\max }=\left(\left(E_{1}+E_{3}\right) / A_{t}\right)-\left(\left(\left(E_{3}-E_{1}\right)^{2}+\left(E_{3}+E_{1}-2 E_{2}\right)^{2}\right)^{1 / 2} / B_{t}\right) \\
\sigma_{\min }=\left(\left(E_{1}+E_{3}\right) / A_{t}\right)+\left(\left(\left(E_{3}-E_{1}\right)^{2}+\left(E_{3}+E_{1}-2 E_{2}\right)^{2}\right)^{1 / 2} / B_{t}\right) \\
\beta=1 / 2 \operatorname{arctang}\left(\left(E_{3}+E_{1}-2 E_{2}\right) /\left(E_{3}-E_{1}\right)\right)
\end{gathered}
$$


where $E_{1}, E_{2}$ and $E_{3}$ are the strains recorded respectively at $0^{\circ}, 225^{\circ}$ and $90^{\circ}$ with a direction of reference, $\sigma_{\max }$ and $\sigma_{\min }$ are the maximum and minimum principal stresses respectively and $\beta$ the angle (measured counter-clockwise) of $\sigma_{\max }$ with the direction of $E_{1}$ (or $\sigma_{\min }$ with the direction of $E_{3}$ ). Fig. 1 shows the dimensions of the analyzed area and the strain gages disposition $\left(E_{1}\right.$ is the strain recorded by the Gage 1 or gage of reference). On the other hand, Standard E837-95 suggests an experimental procedure (laboratory test) to deduce the constants relating the recorded strains to the stresses that cause them. On a sample of the same material as the analyzed on a monument, two strain gages on the centre of a vertical face are glued. The two strain gages are placed in the horizontal and vertical directions over a circumference of $12 \mathrm{~cm}$ diameter. Afterwards the sample is loaded to a known compression stress $(\sigma)$, recording the strains measured in both strain gages which will be called $\mathrm{E}_{\mathrm{hb}}$ (horizontal strain) and $\mathrm{E}_{\mathrm{vb}}$ (vertical strain). With the sample unloaded a drill of the same dimensions as in the analyzed monument is carried out. Afterwards the sample is loaded identically $(\sigma)$ and once more the strains measured by the strain gages are recorded. In this case they will be called $\mathrm{E}_{\mathrm{ha}}$ (horizontal strain) and $\mathrm{E}_{\mathrm{va}}$ (vertical strain). The new constants (called $\mathrm{A}_{\mathrm{s}}$ and $\mathrm{B}_{\mathrm{s}}$ ) are obtained according to the following expressions:

$$
\begin{aligned}
& \mathrm{A}_{\mathrm{s}}=4\left(\left(\mathrm{E}_{\mathrm{va}}-\mathrm{E}_{\mathrm{vb}}\right)+\left(\mathrm{E}_{\mathrm{ha}}-\mathrm{E}_{\mathrm{hb}}\right)\right) /(2 \sigma) \\
& \mathrm{B}_{\mathrm{s}}=4\left(\left(\mathrm{E}_{\mathrm{va}}-\mathrm{E}_{\mathrm{vb}}\right)-\left(\mathrm{E}_{\mathrm{ha}}-\mathrm{E}_{\mathrm{hb}}\right)\right) /(2 \sigma)
\end{aligned}
$$

The principal stresses and their directions can be obtained by using the same expressions mentioned above. Fig. 2 shows the scheme of strain gages position whereas fig. 3 shows the drill device.

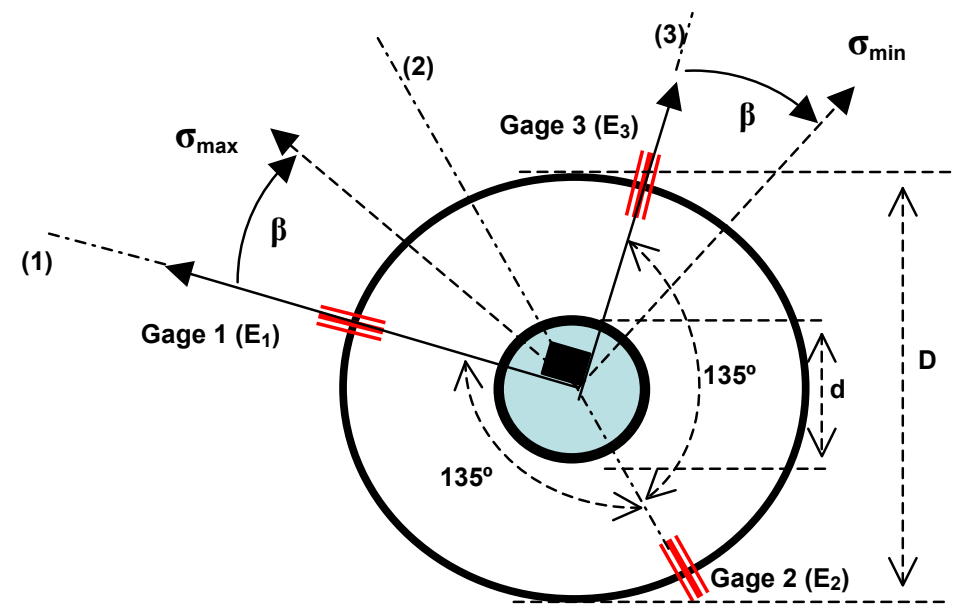

Figure 1: Layout of the geometry for the hole-drilling technique. " $\mathrm{D}$ " is the diameter of the circumference location of the strain gages and " $d$ " is the diameter of the drill. The symbols (1), (2) and (3) show the directions of the strain gages. 
Vertical gage (E1)

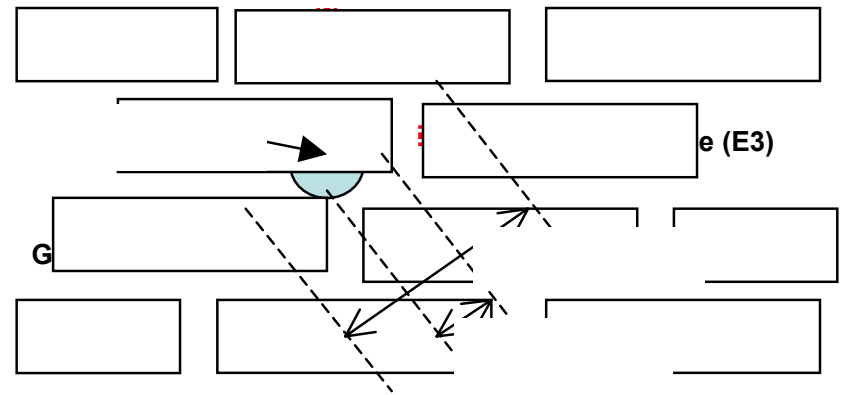

Figure 2: $\quad$ Strain gages disposal. The strain gages are placed on a previously polished surface.

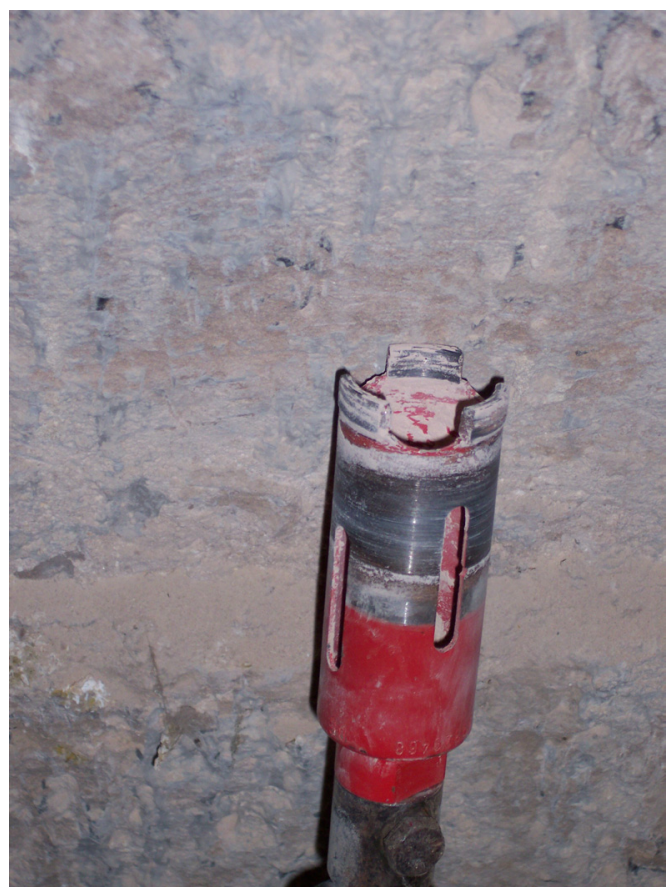

Figure 3: Drill device used for the hole-drilling technique in architectural heritage. 


\section{Laboratory tests}

The hole-drilling technique has been checked on masonry specifically made for this research simulating a structural element of the cultural heritage constructions. The masonry is formed by brick and mortar of medium quality being loaded to a known compressive stress by means of four hydraulic jacks that transmit the force by means of a metallic frame. The objective of this procedure is to compare the applied load with that experimentally deducted by means of the hole-drilling technique. Due to the experimental dimensions of both the drill and the circumference of strain gages the analysis includes two materials: brick and mortar. This means that the constants A and B of brick and mortar together are required.

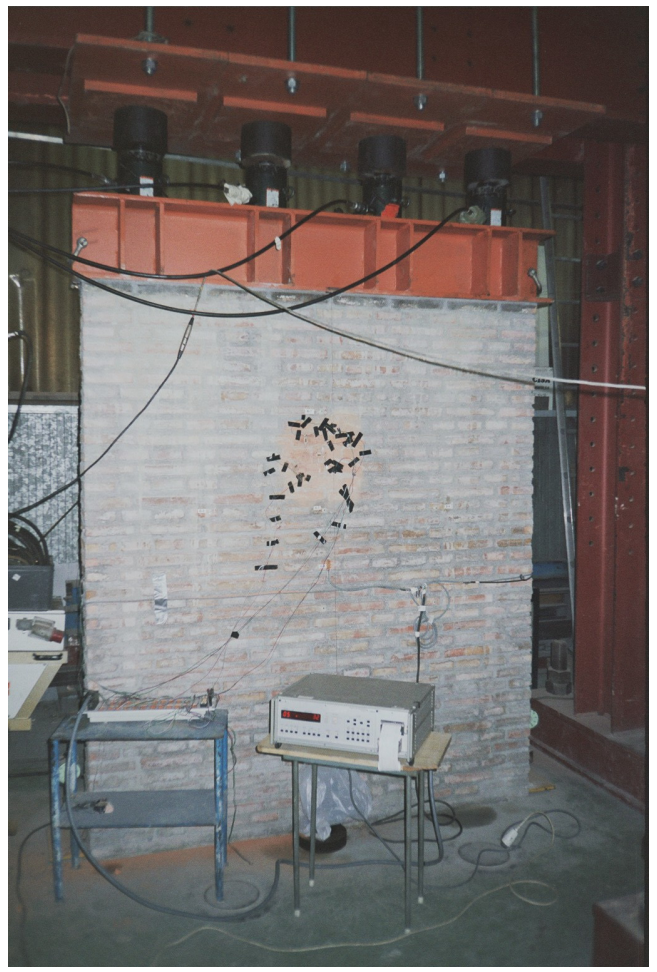

Figure 4: $\quad$ View of the brick masonry and the loading system.

The masonry is composed of one layer with the dimensions of $2.195 \mathrm{~m}$ in height, $1.91 \mathrm{~m}$ in length and $0.24 \mathrm{~m}$ in thickness (fig. 4). Their mechanical properties have been obtained testing the whole masonry as it is explained in the next section. The bricks have a height of $0.035 \mathrm{~m}$, a length of $0.115 \mathrm{~m}$ and a thickness of $0.24 \mathrm{~m}$. Before beginning the tests the "quality" of the load transmission across the metallic frame and the masonries has been checked. For 
this purpose, several optical devices to measure displacements on both sides of the masonry have been placed. It has been detected that the system does not transmit the load uniformly on the two sides.

\subsection{Constants of the brick masonry}

The constants for masonry only can be obtained from the parameters "a" and "b" of the Standard ASTM 837-95 $\left(\mathrm{A}_{t}\right.$ and $\left.\mathrm{B}_{\mathrm{t}}\right)$ and by tests over the whole masonry to obtain both the Young Modulus and the constants $\mathrm{A}_{\mathrm{s}}$ and $\mathrm{B}_{\mathrm{s}}$. That is to say the masonry is considered like a sample. Due to the heterogeneity observed by the load transmission on the brick masonry, the tests to deduce the mechanical characteristics of the brick masonry have been exhaustive. Like the previous task the wall in its entirety has been loaded to a compressive stress of $1.96 \mathrm{~N} / \mathrm{mm}^{2}$ recording the strains measured by 16 optical devices located in several areas of the wall. An average of $4700 \mathrm{~N} / \mathrm{mm}^{2}$ is obtained for the Young Modulus as well as a local variation of the stresses on the two sides between $1.56 \mathrm{~N} / \mathrm{mm}^{2}$ and 2.28 $\mathrm{N} / \mathrm{mm}^{2}$. According to the previous experience on this type of brick masonry it could be coherent to consider a Poisson coefficient of 0.15 . The geometry of strain gages disposal in the brick masonry (fig. 5) slightly changes with respect to the one used on the stone masonry due to the size of the bricks [8]. One has been looking for a circumference of strain gages in order to place each gage on a brick and to centre the drill on another. The mortar is a bad place for both gluing the strain gages and centring the drill. For the brick and mortar dimensions a circumference of $12 \mathrm{~cm}$ in diameter allows it. This layout increases the depth of the drill up to $4.8 \mathrm{~cm}$ to guarantee the complete relaxation of the stresses. According to the Standard ASTM 837-95, the constants a and b are 0.111 and 0.288 respectively, obtaining the constants $A_{t}=-55\left[(\mu \mathrm{m} / \mathrm{m}) /\left(\mathrm{N} / \mathrm{mm}^{2}\right)\right]$ and $\mathrm{B}_{\mathrm{t}}=-120\left[(\mu \mathrm{m} / \mathrm{m}) /\left(\mathrm{N} / \mathrm{mm}^{2}\right)\right]$.

To deduce the experimental constants $\mathrm{A}_{\mathrm{s}}$ and $\mathrm{B}_{\mathrm{s}}$ the masonry has been loaded in its entirety under a stress of $0.8 \mathrm{~N} / \mathrm{mm}^{2}$. Four strain gages have been placed (two on each side) recording the strains in several processes of loading and unloading before and after the drill process. The strains recorded on both sides are detailed in table 1. For Side $\mathrm{E}$ (side viewed on fig. 4) the constants $\mathrm{A}_{\mathrm{sE}}=-50\left[(\mu \mathrm{m} / \mathrm{m}) /\left(\mathrm{N} / \mathrm{mm}^{2}\right)\right]$ and $\mathrm{B}_{\mathrm{sE}}=-75\left[(\mu \mathrm{m} / \mathrm{m}) /\left(\mathrm{N} / \mathrm{mm}^{2}\right)\right]$ are deduced meanwhile for Side I $A_{s I}=-37,5\left[(\mu \mathrm{m} / \mathrm{m}) /\left(\mathrm{N} / \mathrm{mm}^{2}\right)\right]$ and $B_{\mathrm{sI}}=-97,5$ $\left[(\mu \mathrm{m} / \mathrm{m}) /\left(\mathrm{N} / \mathrm{mm}^{2}\right)\right]$ are deduced. The difference between both sides can be originated by a non-uniform transmission of the load inside wall. The proportion of brick and mortar drilled can contribute to these differences. Nevertheless, the drill is made carefully in order to eliminate a similar proportion of brick and mortar. This problem is being investigated by the author. Two average values have been considered, on both sides that is to say $A_{s}=-44\left[(\mu \mathrm{m} / \mathrm{m}) /\left(\mathrm{N} / \mathrm{mm}^{2}\right)\right]$ and $\mathrm{B}_{\mathrm{s}}=-86\left[(\mu \mathrm{m} / \mathrm{m}) /\left(\mathrm{N} / \mathrm{mm}^{2}\right)\right]$.

\subsection{Results for the hole-drilling technique}

According to the methodology described in Section 1, the Hole-drilling technique has been carried out on several areas of the masonry loaded to a 
known stress. Two areas of the brick masonry have been analyzed, one on each side (called Side E and Side I) under a vertical compressive stress of $0.8 \mathrm{~N} / \mathrm{mm}^{2}$. The strains obtained after the drill are shown in table 2. The results of the stresses are shown in fig. 6. The inclinations of the principal directions for both faces are nearly the same (A positive inclination for Side E becomes negative for Side I).

Table 1: Recorded strains by the four strain gages placed in the brick masonry. Two strain gages are placed in Side E and another two on Side I.

\begin{tabular}{|c|c|c|c|c|}
\hline & Ehb $(\mu \mathrm{m} / \mathrm{m})$ & Evb $(\mu \mathrm{m} / \mathrm{m})$ & Eha $(\mu \mathrm{m} / \mathrm{m})$ & Ehb $(\mu \mathrm{m} / \mathrm{m})$ \\
\hline Side E & 5 & -200 & 0 & -175 \\
\hline Side I & 30 & -100 & 18 & -73 \\
\hline
\end{tabular}

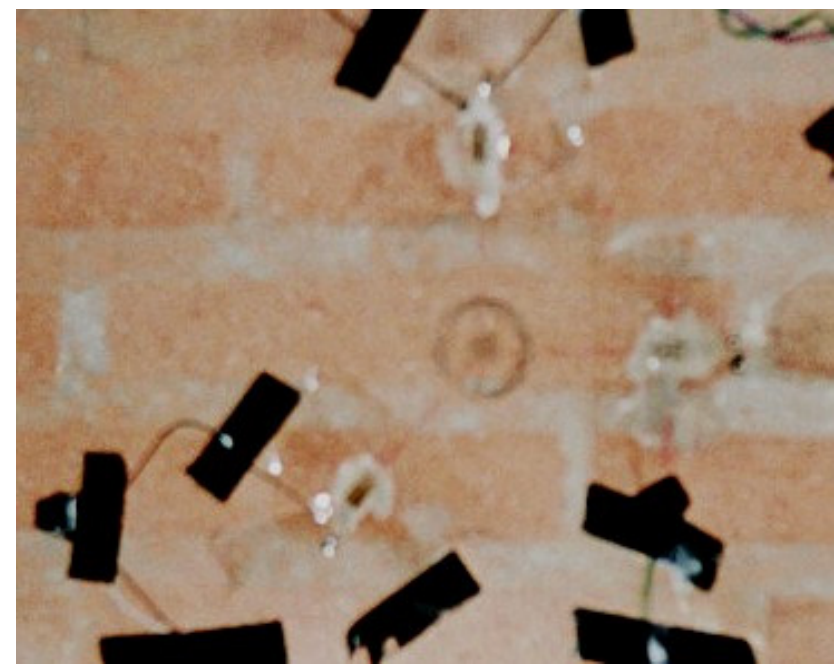

Figure 5: View of the layout of the strain gages before drilling (left) and after (right) drilling.

Table 2: Recorded strains after drilling according to the hole-drilling technique.

\begin{tabular}{|c|c|c|c|}
\hline & E1 $(\mu \mathrm{m} / \mathrm{m})$ & E2 $(\mu \mathrm{m} / \mathrm{m})$ & E3 $(\mu \mathrm{m} / \mathrm{m})$ \\
\hline Side E & 25 & -8 & 0 \\
\hline Side I & 20 & 14 & -10 \\
\hline
\end{tabular}



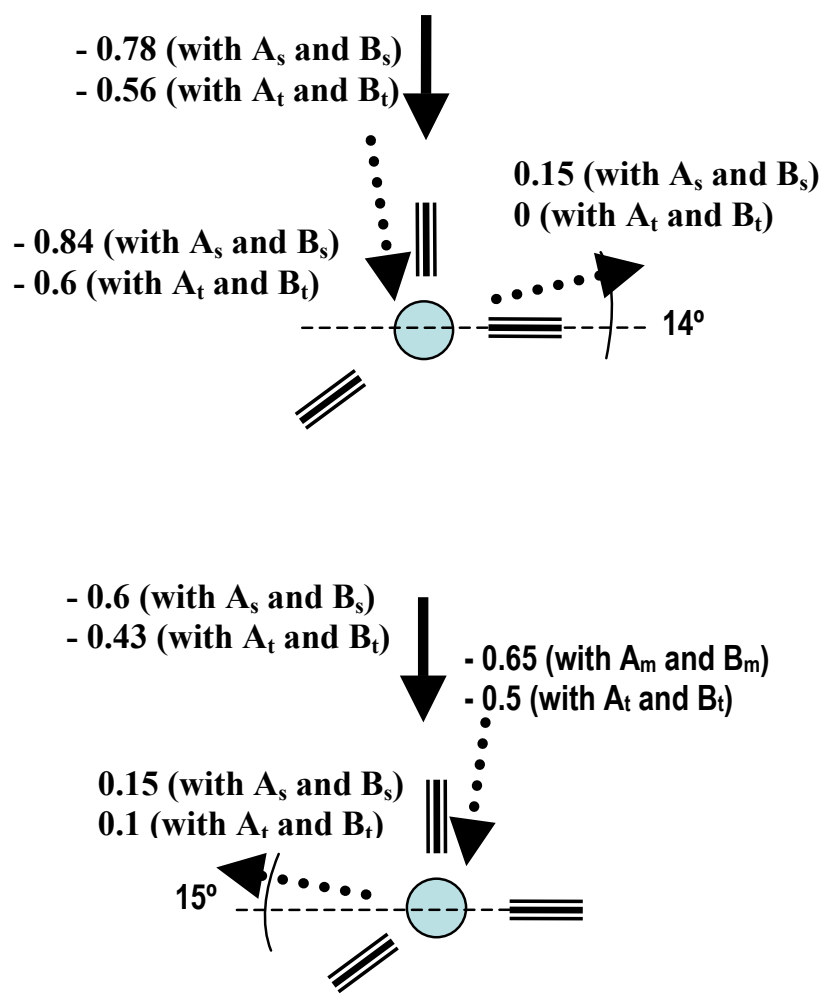

Figure 6: Stress states $\left(\mathrm{N} / \mathrm{mm}^{2}\right)$ on the brick masonry. Principal stresses (inclined arrows) and vertical stresses are shown. The inclinations of the principal directions of both sides are very near (A positive inclination sight from side $\mathrm{E}$ becomes negative from side I).

\section{Discussion}

It has been noticed that it is very difficult to get in practice an ideal state of uniform load distribution on walls tested in the laboratory simulating the walls used in architectural heritage constructions. Although the pressure group transmits a known load, this is not uniformly distributed inside the wall. This situation makes it impossible to get a reference value for the stress in order to compare exactly the results of the hole-drilling technique to the applied stress. The brick masonry has been exhaustively monitored making it possible to deduce that, for an applied stress to the pressure group of $1.96 \mathrm{~N} / \mathrm{mm}^{2}$, the stresses on both sides of the wall varies between $1.56 \mathrm{~N} / \mathrm{mm}^{2}$ and $2.28 \mathrm{~N} / \mathrm{mm}^{2}$. 
That is to say, the stress values in different areas of the wall can change by $+/$ $20 \%$ with respect to the value of the group of pressure. This percentage has been taken as a reference in order to estimate the results as being anomalous or not.

The stresses obtained from $A_{t}$ and $B_{t}$ are lower than those obtained from the constants $A_{s}$ and $B_{s}$. This result has been observed in other previous works [3-9]. The constants $A_{t}$ and $B_{t}$ are obtained from some parameters " $a$ " and "b" (Standard ASTM 837-95) that have been deduced for steel and for experimental dimensions that are much lower than the ones used in this research. Nowadays, the author carries out a Research Project (Reference BIA 2004-04801) financed by the Spanish Government which includes the deduction of the specific constants "a" and " $b$ " for other dimensions. At this moment, the possibility to built and test some samples of brick masonry with reduced dimensions is been investigated. The main problem is repeating the same dimensions for brick and mortar that are observed in a construction on site. Furthermore, the proportion of brick and mortar for each drilling process (Section 1) has to be taken into account because it is expected that the strains recorded vary with the amount of each component that has to be eliminated. This fact affects the values of constants $\mathrm{A}_{\mathrm{s}}$ and $\mathrm{B}_{\mathrm{s}}$.

It can be said that there has been an advance in the final preparation of a technique being alternative and complementary technique to the flat jacks technique [10] in order to deduce the stress states in the cultural heritage constructions. The resistance against drill technique [11-14]) has recently been used for the deduction of the mechanical properties in non-metallic materials. Its experimental procedure is completely different from that described here.

\section{References}

[1] Standard Test Method for Determining Residual Stresses by the HoleDrilling Strain-Gage Method. ASTM 837-95 Standard. American Society for Testing Materials.

[2] Standard Test Method for Determining Residual Stresses by the HoleDrilling Strain-Gage Method. ASTM 837-01 Standard. American Society for Testing Materials.

[3] Barrallo J, Zulueta A, Blanco L, Caro J, Sánchez-Beitia S. Stress measurements on ancient structures by the hole drilling method. Experimental Techniques (SEM) 1994; 19 (3): 9-13.

[4] Barrallo J, Zulueta A, Sánchez-Beitia S. The Donostia Method for stress measurements in architectural heritage. STRAIN (British Society for Strain Measurement) 1999; 35 (3): 107-112

[5] Barrallo J, Zulueta A, Sánchez-Beitia. The Hondarribia City Walls. In Brebbia C, Sánchez-Beitia S, editors. Proceedings of STREMAH 97. Donostia-San Sebastián, 1997. p. 559-565.

[6] Barrallo J, Zulueta A, Sánchez-Beitia S. El Método Donostia en torno a los $20 \mathrm{~kg} / \mathrm{cm} 2$ (In Spanish). Ingeniería Civil 2002; 125: 113-123

[7] Sánchez-Beitia S. Análisis de sistemas portantes en Patrimonio Arquitectónico: relación entre los elementos constructivos y la 
transmisión de cargas (In Spanish). Txertoa Ed. Donostia-San Sebastián 2003.

[8] Sánchez Beitia S. Stresses analysis at the Altes Museum of Berlin by means of the Hole Drilling Technique (Donostia Method). Construction and Buildings Materials (The paper is accepted to publication). Elsevier Ed.

[9] Final Report of the European Project ONSITEFORMASONRY with reference EVK4-CT-2001-00060 (Not published).

[10] Standard Test Method for In Situ Compressive Stress Within Solid Unit Masonry Estimated Using Flatjack Measurements. ASTM C 11Standard. American Society for Testing Materials.

[11] Tiano P., Filareto C., Ponticelli S., Ferrari M. and Valentini E., 2000. "Drilling force measurement system a new standardisable methodology to determine the stone cohesion: prototype design and validation". International Journal for Restoration of Buildings and Monuments, vol 6, $\mathrm{n}^{\circ}$ 2, 2000: 133-150.

[12] G. Exadaktylos, P. Tiano, C. Filareto, "Validation of a model of rotary drilling of rocks with the drilling force measurement system". International Journal for Restoration of Buildings and Monuments, vol 6, $\mathrm{n}^{\circ}$ 3, 2000: 307-340.

[13] Tiano P., Viggiano A., "A new diagnostic tool for the evaluation of the hardness of natural and artificial stones". International Journal for Restoration of Buildings and Monuments, vol 6, $\mathrm{n}^{\circ}$ 5, 2000: 555-566.

[14] J. Delgado Rodriguez and D. Costa "A New Method for Data Correction in Drill Resistance Tests for the Effect of Drill Bit Wear" International Journal for Restoration Internationale Zeitschrift für Bauinstandsetzen Vol. 10, No 3: 1-18 (2004) 